ZOOLOGIA 32 (1): 53-58, February 2015

http://dx.doi.org/10.1590/S1984-46702015000100008

\title{
Trogolaphysa formosensis sp. nov. (Collembola: Paronellidae) from Atlantic Forest, Northeast Region of Brazil
}

\author{
Diego Dias da Silvaํ \& Bruno Cavalcante Bellini 1,2,3
}

\author{
'Programa de Pós-graduação em Sistemática e Evolução, Centro de Biociências, Universidade Federal do Rio Grande do \\ Norte. Campus Universitário Lagoa Nova, 59072-970 Natal, RN, Brazil. E-mail: diegocollembola@gmail.com \\ 2 Departamento de Botânica, Ecologia e Zoologia, Centro de Biociências, Universidade Federal do Rio Grande do Norte. \\ 59072-970 Natal, RN, Brazil. \\ ${ }^{3}$ Corresponding author: E-mail: entobellini@gmail.com
}

\begin{abstract}
Trogolaphysa formosensis sp. nov. (holotype male deposited in DBEZ from Brazil, state of Rio Grande do Norte State, municipality of Bani Formosa), a new springtail from the Atlantic Forest domain, Rio Grande do Norte, Brazil, is described and illustrated. This species is diagnosed by unique coloration pattern, presence of $8+8$ eyes, reduced number of setae on metatrochanteral organ, unguiculi truncated and dorsal chaetotaxy. Trogolaphysa formosensis sp. nov. is the first species of the genus from Brazil with all eye lenses. All other Brazilian species present $0+0$ or $2+2$ eyes. It is also the first species of Trogolaphysa described from the Northeast Region of Brazil.
\end{abstract}

KEY WORDS. Chaetotaxy; Paronellinae; soil fauna; springtail; taxonomy.

The species of Trogolaphysa Mills, 1869 (Paronellinae), one of the most common genera of Paronellidae in the Neotropical Region, are characterized by the following: scales covering dorsal head, dorsal body and ventral face of furcula; fourth antennal segment smooth or annulated, but never subdivided; eyes with 0-8 lenses; labial seta L2 normal; abdominal segments II-IV with $2+2,3+3,3+3$ trichobothria respectively; manubrium lacking spines; dens with 1-2 rows of spines; and mucro short with 3-5 teeth (Soto-Adames \& TAYlor 2013). Trogolaphysa currently comprises 40 described species worldwide, 37 of which are from the New World (Soto-Adames \& TaYLor 2013). It is the largest known genus of Paronellidae in Brazil, holding one third of the known species of the family (five species) (ArLé 1939, Arlé \& Guimarães 1979, Yoshi 1988, Abrantes et al. 2010, 2012).

Herein we describe a new species of Trogolaphysa from the Atlantic Forest of Rio Grande do Norte State, Northeast Brazil. All other Brazilian species are from the Southeast Region. Furthermore, it is the first Brazilian species analyzed based on detailed description of the dorsal chaetotaxy, the most reliable set of characters used to compare species of Entomobryoidea (Szeptycki 1979, Soto-Adames 2008, Soto-Adames \& Taylor 2013).

\section{MATERIAL AND METHODS}

The specimens were collected during the rainy season. The climate of the area is "As" following Koeppen's system, with two distinct seasons: a dry summer and a wet winter (Коттек et al. 2006). Specimens were collected in leaf litter; fixed and preserved in $70 \%$ ethanol; cleared with hydrochloric acid and potassium dichromate; and mounted on glass slides in Hoyer's Medium for study under the optical microscope. Measurements were taken from the holotype; the overall morphology was described based on the entire type series.

The detailed chaetotaxy schemes follow SzEPTYCKI (1979), Soto-Adames (2008) and Soto-Adames \& TAYlor (2013) for dorsal head and body, and Gisin $(1963,1964)$ for labial triangle. Chaetotaxy symbols are presented in Fig. 10. List of abbreviations used in the text: (Abd) abdominal segment; (Ant) antennal segment; (Th) thoracic segment; DBEZ/UFRN: Departamento de Botânica, Ecologia e Zoologia da Universidade Federal do Rio Grande do Norte; CRFS/UEPB: Coleção de Referência para a Fauna de Solo da Universidade Estadual da Paraíba.

\section{TAXONOMY}

\section{Trogolaphysa formosensis sp. nov.}

Figs. 1-20

Description. Habitus entomobryid (Figs. 1 and 2). Color of specimens after fixation in $70 \%$ ethanol, white with darkblue pigment covering Ant I-IV; frontal head, eyepatches, lateral borders of Th II-III and Abd I-III, and one third of Abd IV (Fig. 1). Scales present over Ant I-II, base of Ant III, head, trunk, ventral side of ventral tube, legs, manubrium and ventral dentes.

Head. Ant IV not annulated or subdivided, lacking apical bulb (Fig. 3); Ant III sense organ with two rods and three guard sensillae (Fig. 4); Ant II with two subapical small blunt setae (Fig. 5). Eyes with $8+8$ lenses, posterior lenses $(\mathrm{G}$ and $\mathrm{H})$

2015 | Sociedade Brasileira de Zoologia | www.sbzoologia.org.br | www.scielo.br/zool All content of the journal, except where identified, is licensed under a Creative Commons attribution-type BY-NC. 

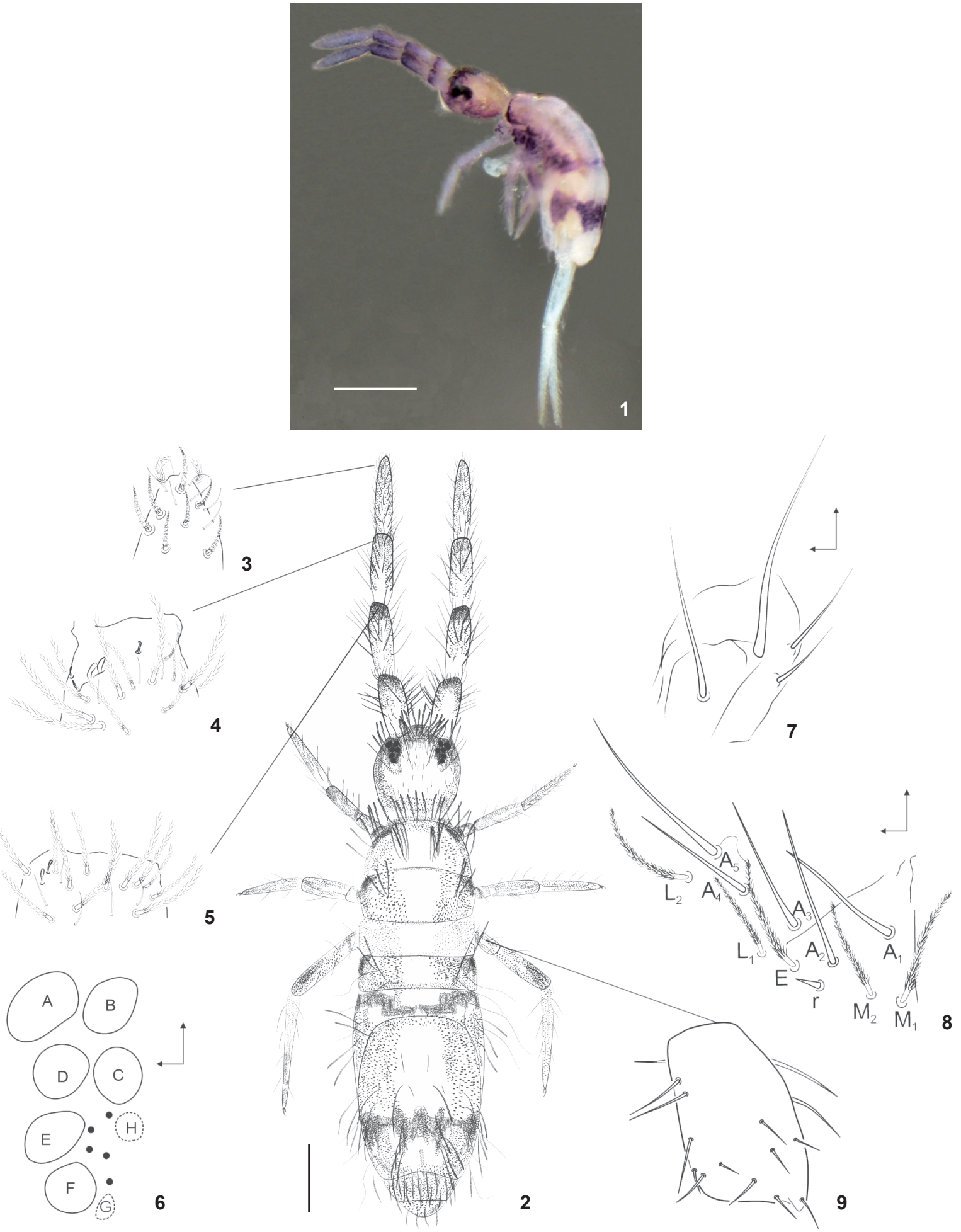

Figure 1-9. Trogolaphysa formosensis sp. nov.: (1) habitus of a fixed specimen in ethanol, lateral view; (2) habitus (dorsal view); (3) apical region of Ant IV (right); (4) apical region of Ant III (right); (5) apical region of Ant II (right); (6) eye patch (left); (7) maxillary palp and sublobal plate (left); (8) labial triangle chaetotaxy (left); (9) metatrochanteral organ. Scale bars: $0.2 \mathrm{~mm}$. 


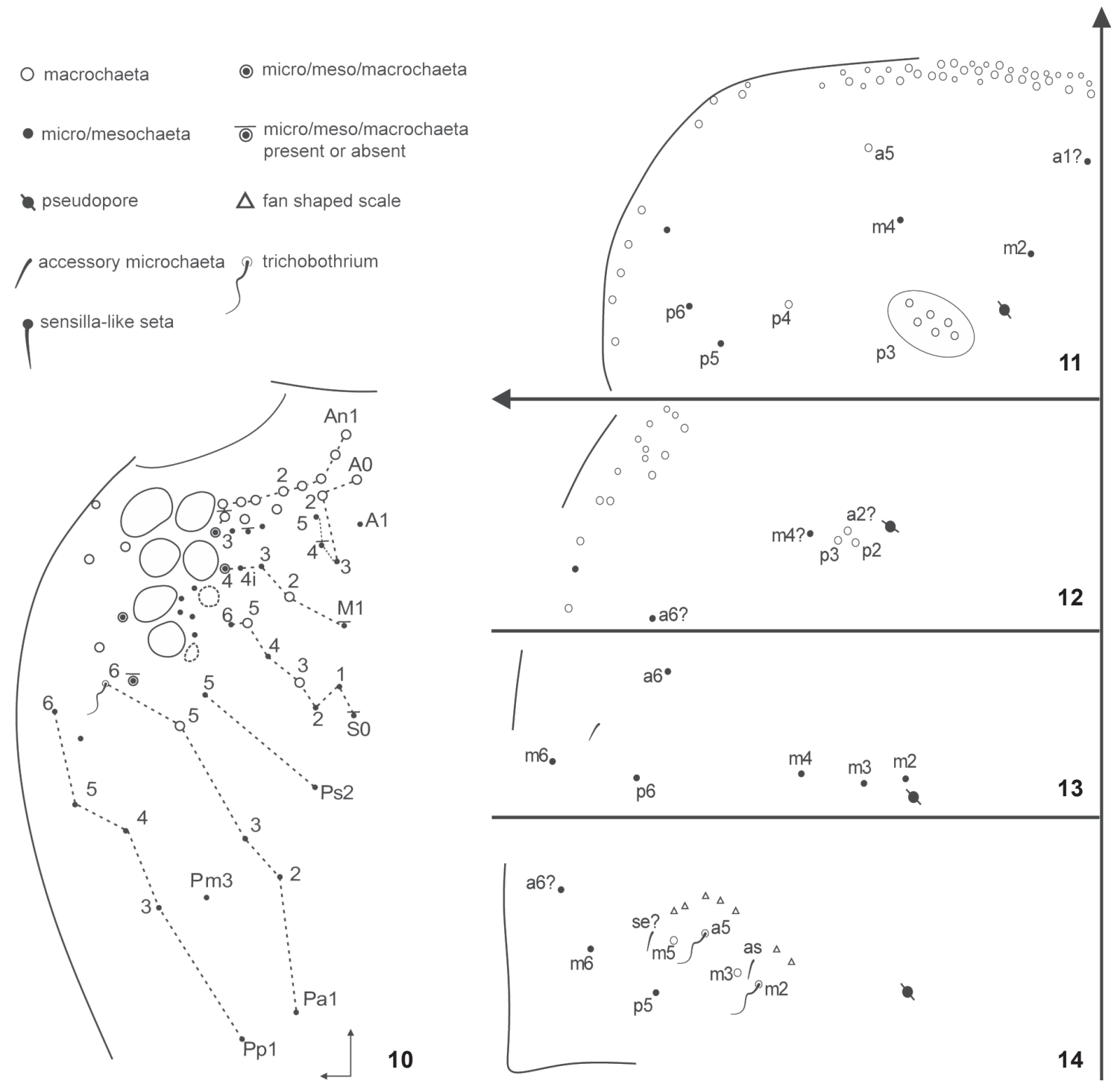

Figures 10-14. Trogolaphysa formosensis sp. nov.: dorsal chaetotaxy (left): (10) head and setae symbols; (11) Th II; (12) Th III; (13) Abd I; (14) Abd II.

vestigial (Fig. 6). Labral setae smooth, prelabral setae feathered; distal margin of labrum lacking spines. Maxillary palp with apical and basal setae smooth; apical seta larger; sublobal plate with 2 smooth appendages (Fig. 7). Labial triangle formula: M1M2rEL1L2/A1-5; r smooth and reduced (Fig. 8). Dorsal head chaetotaxy: 'An' series with 10+10 macrochaetae; 'A' series with $\mathrm{A} 0$ and $\mathrm{A} 2$ as macrochaetae and A1, A3-5 as microchaetae; ' $\mathrm{M}$ ' series with $5+5$ setae, M1, M3, M4i as microchaetae, M2 as macrochaeta, M4 as macro or microchaeta; 'S' series with S0 present as microchaeta, S1, S2, S4, and S6 as microchaetae, S3 and S5 as macrochaetae; interocular series with $5+5$ setae; 'Ps' series with $2+2$ microchaetae (Ps2 and Ps5);
' $\mathrm{Pa}$ ' series with 5+5 setae, $\mathrm{Pa} 1-3$ as microchaetae, $\mathrm{Pa} 5$ as macrochaeta and $\mathrm{Pa} 6$ as trichobothrium; 'Pm' series with $1+1$ microchaetae (Pm3); 'Pp' series with 5+5 microchaetae (Pp6, Pp5, Pp4, Pp3 and Pp1), Pp2 absent (Fig. 10).

Thorax. Dorsal Th II chaetotaxy: 'a' series with 1 internal microchaeta (a1?) and a5 as macrochaeta; ' $m$ ' series with $\mathrm{m} 2$ and $\mathrm{m} 4$ as microchaetae; ' $\mathrm{p}$ ' series with p3 complex arranged as typical for the genus (see SOTO-ADAMEs \& TAYLOR 2013), p4 as macrochaeta, p5 and p6 as microchaetae (Fig. 11). Dorsal Th III cheatotaxy: 3 macrochaetae (a2?, p2 and p3), 1 medial microchaeta (m4?) and 1 external microchaeta (a6?) (Fig. 12). Metatrochanteral organ reduced, with 12 short spines (Fig. 9). 



Figures 15-20. Trogolaphysa formosensis sp. nov.: (15) dorsal chaetotaxy of Abd III (left); (16) dorsal chaetotaxy of Abd IV (left); (17) hind foot complex; (18) distal dens and mucro; (19) genital plate (female); (20) genital plate (male).

Terminal tibiotarsi with capitate tenent hair. External and internal lamellae of ungues with one and three teeth, respectively; outer tooth present (not represented in the figure); unguiculi truncated (Fig. 17).

Abdomen. Dorsal Abd I chaetotaxy: 1 anterior microchaeta (a6) and 5 median microchaetae (m2, m3, m4, p6 and m6) (Fig. 13). Dorsal Abd II chaetotaxy: two trichobothria ( $\mathrm{m} 2$ and a5), surrounded by 2 and 5 fan shaped scales respectively, two macrochaetae (m3 and $\mathrm{m} 5$ ), two accessory sensilla (as and se), and three external microchaetae (p5, m6 and a6?) (Fig. 14). Dorsal Abd III chaetotaxy: three trichobothria (m2, a5 and m5) surrounded by 2, 5 and 2 fan shaped scales respectively, m3, p6, pm6, am6 and m7e? as macrochaetae, am6, m7 and p7 as microchaetae, d2 sensilla present (Fig. 15). Dorsal Abd IV chaetotaxy: 'A' series with $3+3$ setae, A3 and A4 as macrochaetae, A6 as micro or mesochaeta; ' $B$ ' series with $3+3$ macrochaetae (B4-6); 'C' series with $1+1$ micro or mesochaetae (C4); ' $\mathrm{T}$ ' series with $4+4$ setae, T2 and T4 as trichobothria, surrounded by 10 fan shaped scales, T5 as microchaeta and T6 as micro or mesochaeta; ' $\mathrm{Te}$ ' series with $3+3$ setae, Te 1 as macrochaeta, Te2 and Te 3 as micro or mesochaetae; ' $\mathrm{D}$ ' series with $3+3$ setae, $\mathrm{D} 2$ as micro or mesochaeta, D3 as macrochaeta and D4 as 
trichobothrium; ' $E$ ' series with $1+1$ macrochaetae (E3); ' $F$ ' series with $3+3$ macrochaetae (F1-3); 'Fe' series with $1+1$ macrochaetae (Fe3); several sensillae present among the main setae, $15+15$ posterior setae present (Fig. 16). Dentes with 2 rows of ciliated spines; mucro with 4 teeth, with a crest-like structure similar to a fifth tooth (Fig. 18). Genital papillae of male with approximately 20 setae; chaetotaxy of anal valves of female and male as in Figs. 19 and 20, respectively.

Measurements. Total length (head + body) $1.44 \mathrm{~mm}$; body $1.17 \mathrm{~mm}$; longitudinal and transversal head length $0.27 \mathrm{~mm}$ and $0.24 \mathrm{~mm}$ respectively; Ant I-IV respectively: $0.16 \mathrm{~mm}, 0.22$ $\mathrm{mm}, 0.22 \mathrm{~mm}, 0.25 \mathrm{~mm}$; manubrium, dentes and mucro respectively: $0.32 \mathrm{~mm}, 0.24 \mathrm{~mm}, 0.02 \mathrm{~mm}$.

Material examined. Holotype male on slide (DBEZ/ UFRN), BraziL, Rio Grande do Norte State: Baía Formosa Municipality, "Mata Estrela" (06²2'10"S, 3500'28"W), 7.IX.2012, pitfall-trap, D.D. Silva leg. Paratypes: 3 females on different slides (DBEZ/UFRN), 2 females and 2 males on same slide (CRFSUEPB), same date as holotype. Type material deposited at Collembola Collection of DBEZ/UFRN, number 1001; and at CRFS-UEPB, number 5173.

Etymology. The species was named after its type locality, Baía Formosa, Rio Grande do Norte State, Brazil.

Remarks. The new species can be separated from its congeners by the following unique set of characters: color pattern; presence of $8+8$ eyes; reduced number of setae on metatrochanteral organ; unguiculi truncated; and configuration of dorsal chaetotaxy. Trogolaphysa formosensis sp. nov. present setae M1 and M2 in head, Pa series shows five setae, $\mathrm{Pa} 1$ is present, Pp series bears five setae and there are seven macrochaetae on anterior cephalic region (A0, A2, M2, S3, S5 and two unnamed near An series); on thorax, Th II p4 seta is a macrochaeta and there is one extra microseta on Th III (possibly a misplaced a6); on abdomen, Abd II present another extra microseta (also named a6?); on Abd III the sensillum $\mathrm{d} 2$ is posterior to pm6 macrochaeta; and Abd IV present several extra sensillae and B4, E3 and trichobothrium D4 are apparently misplaced. None of these features were seen in other species of the genus (which were analyzed concerning the dorsal chaetotaxy), as shown by the revision of Trogolaphysa by SотоADAMES \& TAYLOR (2013). This particular morphology, combined with Th III wider than Th II; and a distinct mucro shape, with a crest-like structure similar to a fifth tooth, suggest that $T$. formosensis sp. nov. represents an unusual lineage within the genus. However, given that the chaetotaxy of most Brazilian Trogolaphysa have not been described in detail, we do not know if this particular set of characters is unique to this species or to a group of species within Trogolaphysa.

Trogolaphysa formosensis sp. nov. is the only Brazilian species of the genus bearing all eye lenses. All other species present $2+2$ or 0+0 eyes. It differs from T. aelleni Yoshii, 1988, T. hauseri Yoshii, 1988 and T. hirtipes Handschin 1924 also in the color pattern (colored in Trogolaphysa formosensis sp. nov., unpigmented or weakly pigmented on thorax in the other three species) and shape of the unguiculi (truncated in the new species against lanceolated). Trogolaphysa millsi Arlé, 1939 has truncated unguiculi, which is also unpigmented, and its mucro is longer and lacks the crest-like structure seen in the new species. Lastly, the most similar species to Trogolaphysa formosensis sp. nov. among the Brazilian taxa, is T. tijucana Arlé \& Guimarães, 1979, which is also well pigmented and bears truncated unguiculi. However, the color pattern of T. tijucana is restricted to blue pigment covering the antennal segments, Th II-III, Abd I-II, proximal legs and ventral tube. This contrasts with the situation found in Trogolaphysa formosensis sp. nov. which presents blue pigments also over the head, Abd III and IV; furthermore while the new species has dentes with 2 rows of ciliated spines, T. tijucana present dentes with only 1 row of smooth spines (Arlé 1939, Arlé \& Guimarães 1979, Cassagnau 1963, YoshiI 1988).

Trogolaphysa formosensis sp. nov. was collected in the Atlantic Forest, a forestry phytogeographic domain originally ranging from the northern Atlantic coast of Brazil, through Paraguay and northeastern Argentina; within Good's biogeographic zone 27 (Good 1974). All other species of Trogolaphysa seen in Brazil were also collected from this domain, but from the southeastern Region of the country (ARlé 1939, Arlé \& Guimarães 1979, Cassagnau 1963, Yoshi 1988).

\section{ACKNOWLEGMENTS}

Felipe N. Soto-Adames made important suggestions on the drawings. The second author has a grant from the Conselho Nacional de Desenvolvimento Científico e Tecnológico (CNPq)/ Programa de Pesquisa em Biodiversidade - Invertebrados (PPBio).

\section{LITERATURE CITED}

Abrantes EA, Bellini BC, Bernardo AN, Fernandes LH, Mendonça MC, Oliveira EP, Queiroz GC, Sautter KD, Silveira TC, Zeppelini D (2010) Synthesis on Brazilian Collembola: na update to the species list. Zootaxa 2388: 1-22.

Abrantes EA, Bellini BC, Bernardo AN, Fernandes lH, Mendonça MC, Oliveira EP, Queiroz GC, Sautter KD, Silveira TC, Zeppelini D (2012) Errata Corrigenda and update for the "Synthesis of Brazilian Collembola: an update to the species list." Abrantes et al. (2010), Zootaxa 2388: 1-22. Zootaxa 3168: $1-21$.

ArLé R (1939) Collemboles nouveaux de Rio de Janeiro. Annais da Academia Brasileira de Ciências 11: 25-32.

Arlé R, Guimarães AE (1979) Nova espécie do gênero Paronella Schött, 1893 do Rio de Janeiro (Collembola). Revista Brasileira de Entomologia 23 (4): 213-217.

Cassagnau P (1963) Collemboles d'Amérique du Sud, II. Orchesellini, Paronellinae, Cyphoderinae. Biologie de la Amérique Australe 2: 127-148. 
Gisin H (1963) Collemboles d'Europe. V. Revue Suisse de Zoologie 70(5): 77-101.

Gisin H (1964) Collemboles d'Europe. VI. Revue Suisse de Zoologie 71(20): 383-400.

Good R (1974) The geography of flowering plants. London, Longman Group, 574p.

Kottek M, Grieser J, Beck C, Rudolf B, Rubel F (2006) World Map of the Köppen-Geiger climate classification updated. Meteorologische Zeitschrift 15: 259-263.

Soto-AdAmEs FN (2008) Postembryonic development of the dorsal chaetotaxy in Seira downlingi (Collembola, Entomobryidae), with an analysis of the diagnostic and phylogenetic significance of the primary chaetotaxy in Seira. Zootaxa 1683: 1-31.

Soto-Adames FN, Taylor SJ (2013) The dorsal chaetotaxy of Trogolaphysa (Collembola, Paronellidae), with descriptions of two new species from caves in Belize. ZooKeys 323: 3574.

SZEPTYCKI A (1979) Morpho-systematic studies on Collembola. IV. Chaetotaxy of the Entomobryidae and its phylogenetical significance. Kraków, Polska Akademia Nauk, 216p.

Yoshi R (1988) Paronellid Collembola from caves of Central and South America collected by P. Strinati. Revue suisse Zoologie 95 (2): 449-459.

Submitted: 31 October 2014

Received in revised form: 10 December 2014

Accepted: 16 January 2015

Editorial responsibility: Ângelo Parise Pinto 